terials," Am. Scientist, 53 [1] 20-51 (1965).

(a) A. A. Griffith, "Phenomena of Rupture and Flow in Solids," Phil. Trans. Roy. Soc. (London), 221A, 163-98 (1920).

(b) A. A. Griffith, "Theory of Rupture," Proc. First Intern. Congr. A ppl. Mechanics, Delft, pp. 55-63 (1924).

-S. M. Wiederhorn; pp. 503-28 in Materials Science Research, Vol. 3. Edited by W. W. Kriegel and Hayne Palmour III. Plenum Press. New York, 1966.

i S. M. Wiederhorn; pp. 293-317 in Environment-Sensitive Mechanical Behavior of Materials. Edited by A. R. C. Westwood and N. S. Stoloff. Gordon and Breach, New York, 1966.

8 J. J. Gilman, "Direct Measurements of Surface Energies of Crystals," J. Appl. Phys., 31 [12] 2208-18 (1960).

E. B. Shand, "Fracture Velocity and Fracture Energy of Glass in the Fatigue Range," J. Am. Ceram. Soc., 44 [1] 21-26 (1961).

${ }^{10}$ R. J. Charles and W. B. Hillig; pp. 511-27 in Symposium on Mechanical Strength of Glass and Ways of Improving It Florence, Italy, September 25-29, 1961. Union Scientifique Continentale du Verre, Charleroi, Belgium, 1962.

${ }^{11} \mathrm{~W}$. B. Hillig and R. J. Charles, pp. 682-705 in High-Strength Materials. Edited by V. F. Zackey. John Wiley \& Sons Inc. New York, 1965.

12 Samuel Glasstone, K. J. Laidler, and Henry Eyring, Theory of Rate Processes, p. 369. McGraw-Hill Book Co., New York, 1941.

${ }_{18}$ Samuel Glasstone, Textbook of Physical Chemistry, 2d ed.; p. 1201. D. Van Nostrand Co.. Inc., New York, 1946.
${ }^{14}$ R. B. Bird, W. E. Stewart, and E. N. Lightfoot, Transport Phenomena; pp. 519, 529. John Wiley \& Sons, Inc., New York, 1960 .

${ }_{16}$ J. M. Coulson and J. F. Richardson, Chemical Engineering, Vol. I, p. 236. McGraw-Hill Book Co., New York, 1955. ${ }^{16}$ Handbook of Chemistry and Physics, 47th ed.; p. 646. Chemical Rubber Publishing Co., Cleveland, Ohio, 1966.

${ }_{17} \mathrm{~J}$. P. Berry, "Some Kinetic Considerations of the Griffith Criterion for Fracture: I," J. Mech. Phys. Solids, 8 [3] 194-206 (1960).

${ }^{18}$ W. Thomson (Lord Kelvin), "Equilibrium Vapour at a Curved Surface of Liquid," Phil. Mag., 42, 448-52 (1871).

${ }_{19}$ A. N. C. Bennett, "Some Vapor Pressures and Activities of Aqueous Solution of Sodium Silicates," J. Phys. Chem., 31 , 890-96 (1927).

${ }_{20}$ R. W. Harman, "Aqueous Solutions of Sodium Silicates: V," ibid., pp. 355-73.

"21 C. L. Baker and L. R. Jue, "System $\mathrm{Na}_{2} \mathrm{O}-\mathrm{SiO}_{2}-\mathrm{H}_{2} \mathrm{O}$ : Isotherms at $10^{\circ}$ and $31^{\circ} \mathrm{C}$," J. Phys. \& Colloid Chem., 54, 299-304 (1950).

${ }_{22}$ J. H. Wills, "A Review of the System $\mathrm{Na}_{2} \mathrm{O}-\mathrm{SiO}_{2}-\mathrm{H}_{2} \mathrm{O}$," ibid., pp. 304-10.

${ }_{23}$ C. L. Baker, L. R. Jue, and J. H. Wills, "System $\mathrm{Na}_{2} \mathrm{O}-\mathrm{SiO}_{2}$

$\mathrm{H}_{2} \mathrm{O}$ at 50,70 , and $90^{\circ}$ " J. Am. Chem. Soc., 72, 5369-82 (1950)

${ }^{24}$ Stericker; Ph.D. Dissertation, University of Pittsburgh, Pennsylvania, 1922. Values reported in International Critical Tables, Vol. V, p. 16. McGraw-Hill Book Co., New York, 1926-1933.

\title{
Transformation of Quartz to Tridymite in the Presence of Binary Silicate Liquids
}

\author{
GERALD I. MADDEN* and LAWRENCE H. VAN VLACK \\ Department of Chemical and Metallurgical Engineering, The University of Michigan, Ann Arbor, Michigan 48104
}

\begin{abstract}
The isothermal transformation rates for quartz to tridymite were studied in the presence of binary silicate liquids between the eutectic temperature and $1470^{\circ} \mathrm{C}$. Oxide pairs included $\mathrm{Na}_{2} \mathrm{O}$ $\mathrm{SiO}_{2}, \mathrm{PbO}-\mathrm{SiO}_{2}, \mathrm{FeO}-\mathrm{SiO}_{2}$, and $\mathrm{Cu}_{2} \mathrm{O}-\mathrm{SiO}_{2}$. $\mathrm{Mi}-$ crographic and $X$-ray analytical procedures were used. Transformation was most rapid at intermediate temperatures, thus providing typical TTT curves. The rates increased as the liquid contents of the binary pairs were increased. Transformation was more rapid for the pairs which had higher $\mathrm{SiO}_{3}$ contents in their equilibrated liquids. Transformation proceeded as a solution-reprecipitation reaction. Initially, metastable cristobalite precipitated more rapidly than the tridymite; however, it redissolved and eventually disappeared, leaving only tridymite as the solid phase. An empirical equation was adapted to the transformation.
\end{abstract}

\section{Introduction and Previous Work}

$T$ HE reconstructive silica transformations, in contrast to the low-to-high displacive transformations, have been qualitatively described as sluggish. ${ }^{1}$ This investigation was undertaken to determine the effect of temperature and composition on the rate of the reconstructive transformation of quartz to tridymite in the presence of a liquid phase containing $\mathrm{SiO}_{2}$ and another oxide. The systems studied were: $\mathrm{Na}_{2} \mathrm{O}-\mathrm{SiO}_{2}, \mathrm{PbO}-\mathrm{SiO}_{2}, \mathrm{FeO}-\mathrm{SiO}_{2}$, and $\mathrm{Cu}_{2} \mathrm{O}-\mathrm{SiO}_{2}$.

In a study of the influence of iron oxide on the rate of quartz inversion in lime and lime-clay bonded silica brick,
Hugill and Rees ${ }^{2}$ found that the transformation of quartz to tridymite was promoted by the presence of iron oxide, but obtained no quantitative information to describe the reaction rates. In addition, they observed that the presence of tridymite increased the cross-breaking strength, the modulus of rupture, and the crushing strength of brick.

Grimshaw et al. ${ }^{3}$ studied the kinetics of quartz transformation in the presence of various additives $\left(\mathrm{Fe}_{2} \mathrm{O}_{3}, \mathrm{CaO}, \mathrm{MgO}\right.$, $\mathrm{Al}_{2} \mathrm{O}_{3}$, and $\mathrm{TiO}_{2}$ ). The important factors in the transformation process were the presence of liquid, subdivision of the solid catalysts, and the type of oxide added.

A study of the effects of the addition of alkali oxides to quartz on the formation of tridymite was reported by De Keyser and Cypres, ${ }^{4}$ who found that tridymite forms more rapidly in the presence of $\mathrm{Na}_{2} \mathrm{O}$ and $\mathrm{K}_{2} \mathrm{O}$ than in the presence of $\mathrm{Li}_{2} \mathrm{O}$ at the same molar concentrations and temperatures. The

Presented at the Sixty-Eighth Annual Meeting, The American Ceramic Society, Washington D. C. May 10, 1966 (Basic Science Division, No. 35-B-66). Received January 20, 1966; revised copy received January $30,1967$.

This work forms part of a thesis submitted by G. I. Madden in partial fulfilment of the requirements for the degree of Doctor of Philosophy in metallurgical engineering, Horace Rackham School of Graduate Studies, The University of Michigan, 1965.

This work was supported by the United States Office of Naval Research under Contract No. Nonr 1224(47).

At the time this work was done the writers were, respectively, graduate student, and professor and associate chairman, Department of Chemical and Metallurgical Engineering, The University of Michigan.

* Now research scientist, Paul D. Merica Research Laboratory, The International Nickel Company, Incorporated, Sterling Forest, Suffern, New York 10901. 
rate of the transformation was related to the amount of liquid formed in the respective systems. Furthermore, as the liquid phase became more viscous, the rate was reduced.

A study of the reaction rates of silica in the presence of other oxides at various temperatures has also been reported by Abou-El-Azm and Moore. ${ }^{5}$ The purpose of their investigation was to determine the rate at which glass is formed when silica is heated in the presence of another oxide. In both the binary and the ternary systems, the rate of reaction was dependent on the amount and type of oxides in the following order: $\mathrm{K}_{2} \mathrm{O}$ (greatest effect), $\mathrm{Na}_{2} \mathrm{O}, \mathrm{B}_{2} \mathrm{O}_{3}$, $\mathrm{CaO}, \mathrm{MgO}$ (least effect). They also found that the rate is influenced by the amount of liquid formed in the various systems studied.

Quartz does not transform directly to tridymite in the upper temperature range of tridymite stability. Instead, cristobalite forms as an intermediate metastable phase. Thus, the reaction is usually considered to be:

$$
\text { quartz } \rightarrow \text { cristobalite } \rightarrow \text { tridymite }
$$

Although this reaction has been assigned as appropriate by most previous investigators, it is shown later that most probably quartz forms cristobalite and tridymite concurrently but at different rates; the metastable cristobalite subsequently transforms to the stable tridymite.

\section{Experimental Procedure}

\section{(1) Specimen Preparation}

The raw materials included 140-mesh reagent grade powders of quartz, $\mathrm{PbO}, \mathrm{Fe}_{2} \mathrm{O}_{3}$, and $\mathrm{Na}_{2} \mathrm{SiO}_{3}$. These materials were mixed in the desired amounts and then pressed into pellets and placed on a sheet of platinum which, in turn, was placed on an alumina combustion boat and fired in a resistance furnace heated by silicon carbide heating elements transverse to two combustion tubes. The furnace temperature was automatically controlled by a Pt-Pt10Rh thermocouple placed between the two furnace tubes. The specimen temperature was measured separately by a second thermocouple within the furnace tubes that had been checked against a thermocouple calibrated by the National Bureau of Standards. The temperature readings were accurate to $\pm 5^{\circ} \mathrm{C}$, including the $\pm 2^{\circ} \mathrm{C}$ variation possible in the NBS thermocouple. After firing, the specimens were water-quenched to preserve the phases present at the firing temperature.

\section{(2) Specimen Analysis}

Two methods of analysis were used: (1) point-counting on reflected-light specimens for the $\mathrm{Cu}_{2} \mathrm{O}-\mathrm{SiO}_{2}$ system, and (2) $\mathrm{X}$-ray analyses for the $\mathrm{PbO}-\mathrm{SiO}_{2}, \mathrm{FeO}-\mathrm{SiO}_{2}$, and $\mathrm{Na}_{2} \mathrm{O}-$ $\mathrm{SiO}_{2}$ systems.

(A) Point-Count Analyses: In the $\mathrm{Cu}_{2} \mathrm{O}-\mathrm{SiO}_{2}$ system, the difference in morphology of the solid phases and the differences in reflectivity between the solid and liquid phases made it possible to analyze the specimens by a reflected-light ceramographic technique. Specimens were mounted in either a Bakelite or polyester resin and then impregnated with a thermosetting resin to prevent pulling out any of the phases during polishing. The specimens were polished with 400 and 600 grit papers, followed by 8 and $1 \mu$ diamond polishing wheels. In the point-counting procedure approximately 250 points were used on each specimen.

(B) X-Ray Analyses: In the $\mathrm{FeO}-\mathrm{SiO}_{2}, \mathrm{PbO}-\mathrm{SiO}_{2}$, and $\mathrm{Na}_{2} \mathrm{O}-\mathrm{SiO}_{2}$ systems, where the optical procedure of pointcounting was less satisfactory, we used a quantitative $\mathrm{X}$-ray technique based on the 4.31 and $4.04 \mathrm{~A}$ peaks of tridymite and cristobalite, respectively. The method of Holmquist et $a .^{6}$ was modified to be similar to the technique described by Klug and Alexander.' The specimen was ground into a uniform powder, and the powder was exposed to $X$ rays in a recording diffractometer. The areas under the 4.31 and 4.04 A peaks for tridymite and cristobalite were measured and
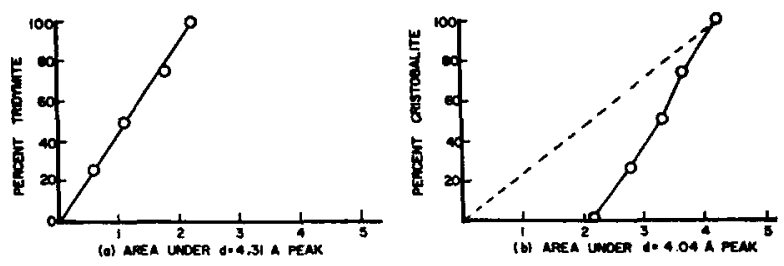

Fig. 1. X-ray standard curves for the $\mathrm{Na}_{2} \mathrm{O}-\mathrm{SiO}_{2}$ system. Specimens contained $10 \%$ liquid. (In $(b)$, the $4.04 \mathrm{~A}$ cristobalite peak overlaps other reflections; therefore it does not drop to zero.)

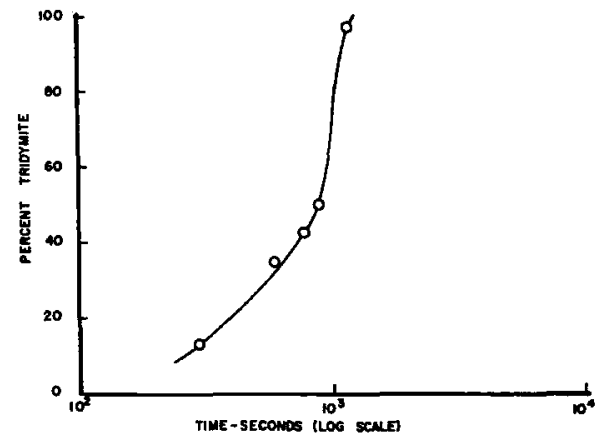

Fig. 2. Firing time vs. percent tridymite. $\mathrm{Na}_{2} \mathrm{O}-\mathrm{SiO}_{2}$ specimens containing $40 \%$ liquid, fired at $1250^{\circ} \mathrm{C}$.

compared with standard curves of known mixtures of tridymite and cristobalite. The standard deviation with this method was about $3 \%$. The standard curves had been prepared by mixing known ratios of cristobalite and tridymite which had been ground to approximately -325 mesh. (The ratios included $0 / 100,25 / 75,50 / 50,75 / 25$, and $100 / 0$ weight ratios of the two phases.) The cristobalite had previously been prepared by firing quartz in the presence of the added oxide at $1500^{\circ} \mathrm{C}$ for $5 \mathrm{hr}$. The tridymite was prepared by firing quartz in the presence of the added oxide at $1250^{\circ} \mathrm{C}$ for approximately two weeks to remove all remnants of quartz and cristobalite. In preparing standard materials, account was taken of the effect of the temperature and total composition on the amount of the crystalline silica phases within the system.

These mixtures were then analyzed in a rotating sample holder on a Norelco diffractometer operated at $37 \mathrm{kv}$ and 12 ma, using copper radiation. The beam slit and the detector slit were both $1^{\circ}$. The unit was equipped with a GeigerMueller detector and a recording apparatus made by Norelco. The areas were measured with a compensating polar planimeter. The resulting standard curves are presented in Fig. 1. There was no evidence of change in lattice dimensions.

A semilogarithmic plot of time versus percent tridymite (Fig. 2) shows the time to $50 \%$ transformation to tridymite. This time was chosen to describe the reaction kinetics and was plotted as a function of temperature at a constant liquid content to illustrate the effect of the various parameters on the reaction.

\section{Results and Discussion}

As referred to in the foregoing, the transformation of quartz to tridymite in the presence of a liquid does not occur directly. Cristobalite forms as an intermediate metastable phase that subsequently transforms to the stable tridymite in the upper range of tridymite stability. The initial step in the transformation, the dissolution of quartz and formation of cristobalite, occurs rapidly compared to the subsequent 

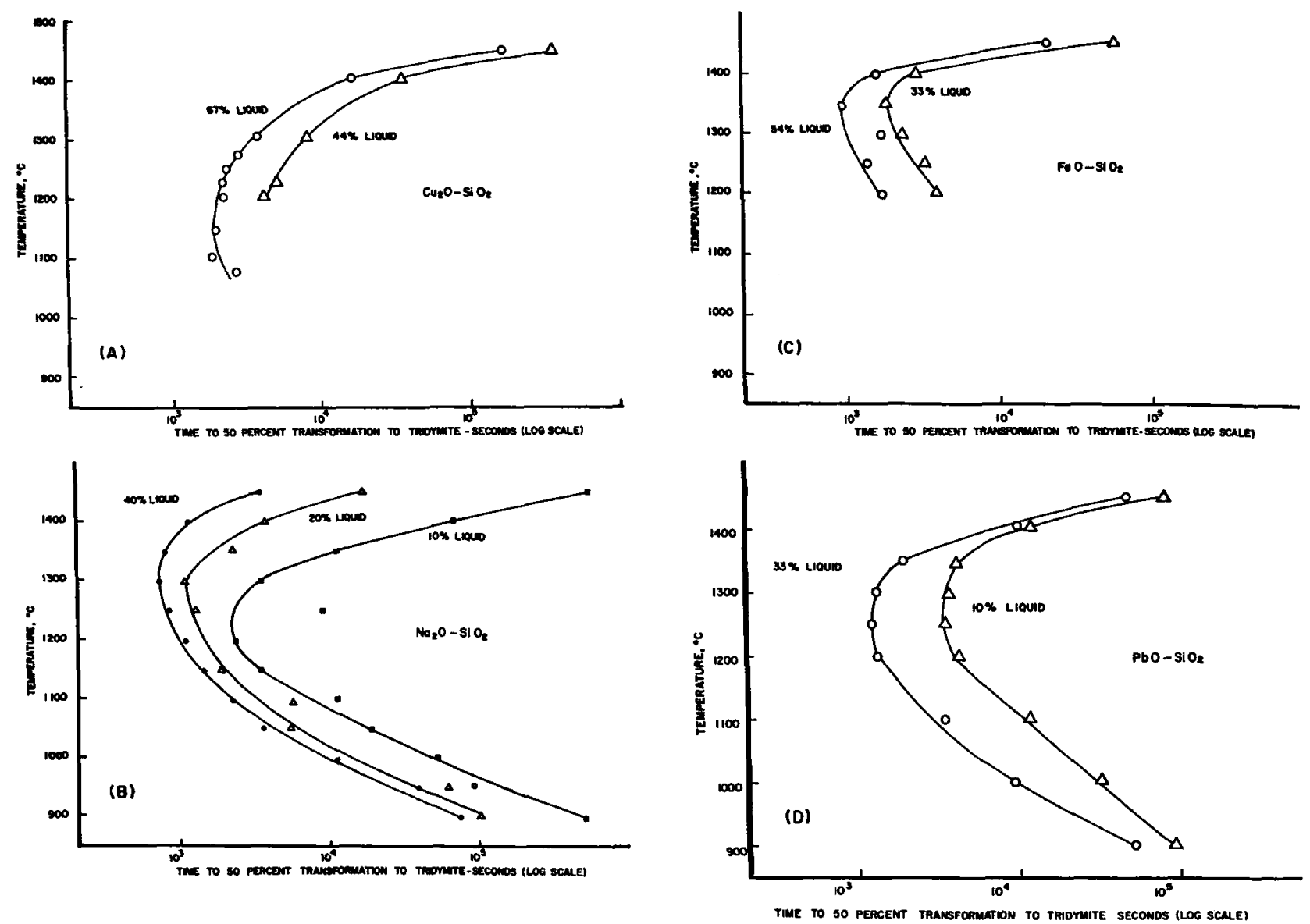

Fig. 3. Isothermal transformation diagram for the system:

(A) $\mathrm{Cu}_{2} \mathrm{O}-\mathrm{SiO}_{2},(B) \mathrm{Na}_{2} \mathrm{O}-\mathrm{SiO}_{2}$, (C) $\mathrm{FeO}_{-} \mathrm{SiO}_{2}$, and (D) $\mathrm{PbO}-S i O_{2}$.

steps that involve the final precipitation of stable tridymite. This transformation sequence was observed in all four systems studied.*

The results gave the isothermal transformation diagrams (variously called time-temperature-transformation diagrams, TTT diagrams, and $C$ curves) shown in Figs. $3(A)$ through (D). These semilogarithmic plots show that the reaction is slow near the upper temperature range for tridymite stability $\left(1470^{\circ} \mathrm{C}\right)$, but as the temperature is decreased, the reaction rate increases until a maximum is reached. Below this temperature, the time for transformation is lengthened. In each case, the lower limit for study was the eutectic temperature. This behavior is similar to that observed in studies of the kinetics of devitrification and crystal growth in glass ${ }^{8,9}$ and parallels many of the metallic isothermal transformations typified by the eutectoid decomposition of $\mathrm{Fe}-\mathrm{C}$ alloys.

\section{(1) Amount of Liquid}

Increasing the amount of liquid increased the rate of transformation at a given transformation temperature (Figs. $3(A)$ through $(D)$ ). For a given size of the individual solid grains, increasing the amount of liquid also increases the solid-liquid boundary area per unit volume. The solid-liquid boundary

* Subsequent work has shown that the cristobalite-quartz metastable equilibrium temperature is $880^{\circ} \pm 5^{\circ} \mathrm{C}$ in the $\mathrm{Na}_{2} \mathrm{O}-\mathrm{SiO}_{2}$ system, and that cristobalite does not form as a metastable phase below that temperature. All data in this paper, however, are for $900^{\circ} \mathrm{C}$ and above where cristobalite does form.
Table I. Comparison of Relative Area-to-Volume Ratio with Amount of Liquid and Transformation Rate for the $\mathrm{Cu}_{2} \mathrm{O}-\mathrm{SiO}_{2}$ System

\begin{tabular}{cccc}
\hline $\begin{array}{c}\text { Firing } \\
\text { temp. }\left({ }^{8} \mathrm{C}\right)\end{array}$ & $\begin{array}{c}\text { Amount } \\
\text { of liquid (\%) }\end{array}$ & $\begin{array}{c}\text { Area-to-volume } \\
\text { ratio, Sv }\end{array}$ & $\begin{array}{c}\text { Time for 50\% } \\
\text { transformation to } \\
\text { tridymite (sec) }\end{array}$ \\
\hline 1440 & 44 & 104 & 360,000 \\
& 67 & 220 & 180,000 \\
1300 & 44 & 92 & 8,100 \\
& 67 & 176 & 6,480 \\
1250 & 44 & 84 & 4,860 \\
& 67 & 220 & 2,400 \\
\hline
\end{tabular}

area is the area of the solid grains exposed to the liquid phase and can be measured by

$$
S_{\mathrm{v}}=2 P_{L}
$$

where $S_{v}$ is the solid-liquid boundary area per unit volume of the specimen and $P_{L}$ is the number of solid-liquid phase boundaries traversed by a random line. ${ }^{10}$ Table I summarizes the data obtained in the $\mathrm{Cu}_{2} \mathrm{O}-\mathrm{SiO}_{2}$ system on polished sections of specimens having different liquid contents. The amount of liquid in the specimens was varied by varying the amounts of $\mathrm{Cu}_{2} \mathrm{O}$ and $\mathrm{SiO}_{2}$ raw materials. The results show that increasing the area of the solids exposed to the liquid phase, $S_{v}$, decreases the time necessary to reach $50 \%$ transformation to tridymite. With more solid area exposed to the liquid phase the possibilities for solution and reprecipitation of the transforming phases are increased. 
Table II. Summary of Liquid Composition and Transformation Rates at $1300^{\circ} \mathrm{C}$ for Specimens Containing $30 \%$ Liquid

\begin{tabular}{|c|c|c|}
\hline System & $\begin{array}{c}\text { Silica in } \\
\text { liquid phase (mole \%) }\end{array}$ & $\begin{array}{l}\text { Time for } 50 \% \\
\text { transformation to } \\
\text { tridymite (sec) }\end{array}$ \\
\hline $\begin{array}{l}\mathrm{Na}_{2} \mathrm{O}-\mathrm{SiO}_{2} \\
\mathrm{PbO}-\mathrm{SiO}_{2} \\
\mathrm{FeO}-\mathrm{SiO}_{2} \\
\mathrm{Cu}{ }_{2} \mathrm{O}-\mathrm{SiO}_{2}\end{array}$ & $\begin{array}{l}83 \\
76 \\
44 \\
29\end{array}$ & $\begin{array}{l}1000 \\
1400 \\
2000 \\
9000\end{array}$ \\
\hline
\end{tabular}

\section{(2) Liquid Composition}

The curves presented in Figs. $3(A)$ through $(D)$ also show that, with a constant amount of liquid, the rate of transformation decreases as a function of the added oxide in the following order: $\mathrm{Na}_{2} \mathrm{O}$ (fastest), $\mathrm{PbO}, \mathrm{FeO}, \mathrm{Cu}_{2} \mathrm{O}$ (slowest).

When the liquid phase contained a higher concentration of $\mathrm{SiO}_{2}$, the maximum rate of transformation to tridymite increased (Table II). Since the concentration of the accompanying oxide was lower in the liquid, there was less solute to diffuse from the interface between the liquid and solid phases, permitting a more rapid crystallization of the tridymite from the liquid.

\section{(3) Transformation Reactions}

This study, as well as previous studies, indicates that the transformation of quartz to tridymite occurs much more rapidly in the presence of an oxide-liquid than in a completely solid system. Furthermore, the reaction is completed more rapidly as the amount of liquid is increased. Thus, it may be concluded that the most rapid transformation occurs by a solution-reprecipitation process.

On the basis of the observation that a liquid exists as an intermediate phase between succeeding solid phases, it is necessary to revise the tacit assumption that all the quartz transforms to cristobalite with the cristobalite then transforming to tridymite. Such an assumption would require that the sequence be quartz $\rightarrow$ liquid $\rightarrow$ cristobalite $\rightarrow$ liquid $\rightarrow$ tridymite, with each step achieving somewhat lower free energy (with the consequence that the same liquid appears at two energy levels).

A somewhat more plausible mechanism may be illustrated by the following equation showing a solution of the quartz and a concurrent precipitation of both cristobalite and tridymite from the liquid:

$$
\underset{\text { quartz }}{\rightarrow} \underset{\substack{\downarrow \\ \text { cristobalite }}}{\rightarrow} \rightarrow \text { tridymite }
$$

On this basis, reaction kinetics favor an initial accumulation of metastable cristobalite from the liquid (Fig. $4(A)$ ); however, as the more stable tridymite slowly precipitates (Fig. $4(B)$ ), there is a gradual resolution of the cristobalite into the same liquid until the final cristobalite disappears (Fig. $4(C)$ ). This analysis indicates that of the possible mechanisms involved in the transformation of quartz to tridymite the one of primary importance is solution and precipitation. However, the extent of the roles of cristobalite solution and tridymite precipitation as rate-limiting steps was not determined in this study.

\section{(4) Empirical Relations}

Inasmuch as the time requirements for transformation are similar to those observed in studies of the kinetics of the devitrification and crystal growth of glass, ${ }^{8,9}$ it was considered advantageous to use previously developed empirical relations in this study. The rate of crystal growth in glass increases as the difference between the growth temperature and the liquidus temperature is increased. The growth rate reaches a maximum and then decreases in proportion to the reciprocal of the melt viscosity. This process has been described by Swif $^{8}{ }^{8}$ using the following relation:

$$
U=\frac{\text { (constant) }\left(T_{0}-T_{i}\right)}{\eta^{2}}
$$

where $U$ is the crystal grow th rate, $T_{0}$ is the liquidus temperature, $T_{i}$ is the temperature at the growing interface, and $\eta$ is the melt viscosity which varies extensively with temperature. Equation (1) is based on an empirical relation between crystal growth rate and the temperature for viscous liquids originally presented by Preston ${ }^{11}$ :

$$
U=K\left(T_{0}-T_{i}\right) e^{-C / T_{i}}
$$

where $K$ and $C$ are constants, and temperatures are expressed in absolute degrees. Preston found that two assumptions were experimentally justifiable for the temperature regions above and below $T_{\max }$, the temperature at which the rate of crystal growth is at a maximum. In the temperature interval between $T_{\max }$ and the eutectic temperature, the rate of crystal growth was proportional to the difference between the liquidus temperature and the temperature at the growing interface. Preston considered this temperature difference to be the degree of supercooling and a measure of the force causing crystallization. Below $T_{\max }$ the viscosity of the liquid, which increases rapidly as the temperature is decreased, is assumed to be responsible for the decrease in crystal growth rate despite the continual increase in the degree of supercooling.
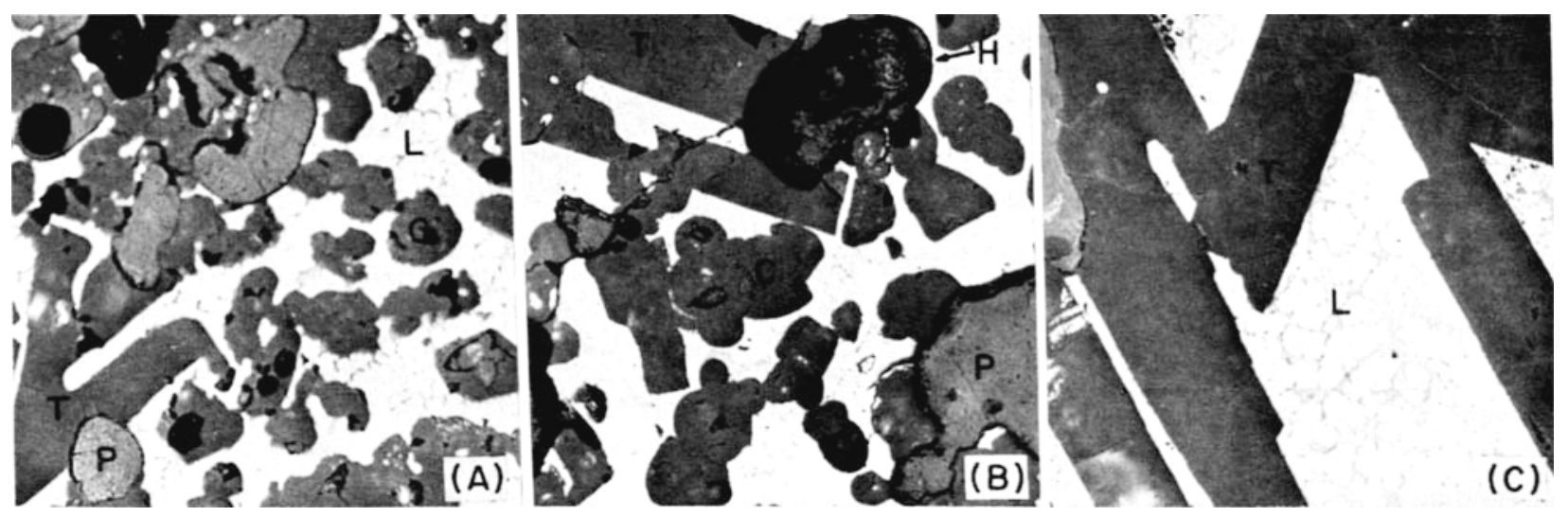

Fig. 4. Specimens containing $50 \mathrm{SiO}_{2}-50 \mathrm{Cu}_{2} \mathrm{O}(w \mathrm{t} \%)$ fired at $1400{ }^{\circ} \mathrm{C}$. (A) Fired $1 \mathrm{hr}, 10 \%$ tridymite; $(B)$ fired $4 \mathrm{hr}, 37 \%$ tridymite; and $(C)$ fired $72 \mathrm{hr}, 100 \%$ tridymite. $T=$ tridymite, $C=$ cristobalite, $L=$ liquid, $P=$ impregnating plastic, and $H=$ hole. $(\times 230$. 
To determine the applicability of the type of analysis described above to the present investigation, the following empirical relation was used:

$$
R=K\left(T_{c}-T_{i}\right)-c / r_{i}
$$

where $R$ is the rate of transformation of quartz to tridymite at temperature $T_{\mathfrak{t}}, T_{c}$ is the tridymite-cristobalite equilibrium temperature $\left(1470^{\circ} \mathrm{C}, 1743^{\circ} \mathrm{K}\right), C$ is a constant that can be determined from the slope of the linear semilogarithmic plot of $R$ versus the reciprocal of the absolute temperature, and $K$ is a constant. Semilogarithmic plots of $R$ versus $1 / T_{i}$ for values of $T_{i}$ lower than $T_{\max }$ gave two possible values for $C$ because of a break in the curve, as shown in Fig. 5. The value of $C$ was obtained from the lower temperature portion of the curve because this part of the curve best described the process taking place below $T_{\max }$. Figure 5 was obtained from data in the $\mathrm{Na}_{2} \mathrm{O}-\mathrm{SiO}_{2}$ system at $40 \%$ liquid concentration; the value for $C$ obtained from this figure was used in Eq. (3) to calculate $\left(1743^{\circ} \mathrm{K}-T_{i}\right) e^{-c / T_{i}}$. These values were then plotted versus temperature as shown in Fig. 6. This figure agrees with the experimental curve obtained for this composition and system, both in the shape of the curve and the temperature at which the rate becomes a maximum. Calculations were also made at the $20 \%$ liquid level in the $\mathrm{Na}_{2} \mathrm{O}-\mathrm{SiO}_{2}$ system and the $30 \%$ liquid level in the $\mathrm{PbO}-\mathrm{SiO}_{2}$ system. These results are also in agreement with the experimental findings. In the $\mathrm{Cu}_{2} \mathrm{O}-\mathrm{SiO}_{2}$ and $\mathrm{FeO}-\mathrm{SiO}_{2}$ systems, the semilogarithmic plots of temperature versus the calculated value for $\left(1743^{\circ} \mathrm{K}-T_{i}\right) e^{-C / T_{i}}$ did not show the full $C$ curve because $T_{\max }$ occurs near the eutectic temperature and a less accurate value of $C$ was obtained.

\section{Conclusions}

(1) The rate of transformation of quartz to tridymite in the presence of other oxides is affected by the amount of liquid present at the transformation temperature, the type of oxide present in the silicate liquid, and the temperature at which the transformation occurs. The kinetics of the transformation show the characteristics of a $C$ curve. The transformation proceeds slowly near the upper temperature limit of tridymite stability $\left(1470^{\circ} \mathrm{C}\right)$ and at temperatures near the eutectic and passes through a maximum in an intermediate range.

(2) The transformation rate increases as the liquid content is increased because the amount of solid/liquid boundary area increases compared with the amount of crystalline silica present. Admittedly, there are several atomic mechanisms that are probably important in the transformation of silica from one polymorphic phase to another. The relation just cited, however, indicates that the solution-precipitation steps are very important and possibly are the ratecontrolling steps.

(3) The rate of transformation of quartz to tridymite is related to the solubility of silica in the liquid phase. The transformation rate decreased in the following order: $\mathrm{Na}_{2} \mathrm{O}$ (fastest), $\mathrm{PbO}, \mathrm{FeO}, \mathrm{Cu}_{2} \mathrm{O}$ (slowest). The extent of solubility of silica in the liquid phase decreases in the same order, suggesting that higher silica contents give more rapid precipitation on the surface.

(4) The following empirical equation has been formulated to describe the rate of transformation $R$ :

$$
R=K\left(1743^{\circ} \mathrm{K}-T_{i}\right) e^{-c / r_{i}}
$$

In this equation $C$ and $K$ are constants, and $T_{i}$ is the specific temperature of interest. The validity of this relation is dependent on the accuracy of the value obtained for the constant $C$. The part of the isothermal curve below $T_{\max }$ (the temperature at which the rate is at a maximum) is taken into account by the factor $e^{-c / T_{i}}$. The part of the curve above $T_{\max }$ is related to the term $\left(1743^{\circ} \mathrm{K}-T_{\imath}\right)$, where $1743^{\circ} \mathrm{K}$ is the tridymite-cristobalite equilibrium temperature of $1470^{\circ} \mathrm{C}$.

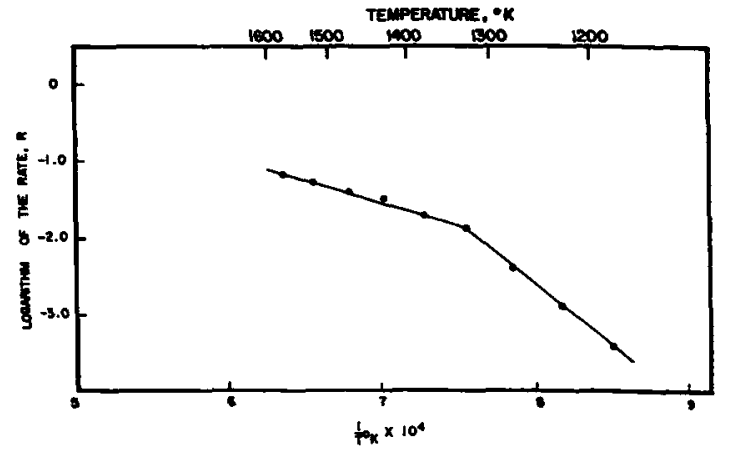

Fig. 5. Logarithm of rate, $R$, vs. reciprocal absolute tempera ture for $\mathrm{Na}_{2} \mathrm{O}-\mathrm{SiO}_{2}$ specimens containing $40 \%$ liquid.

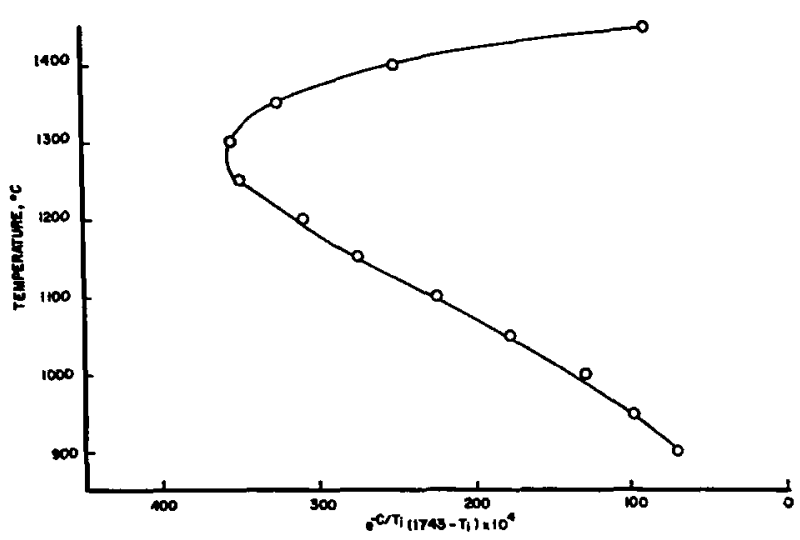

Fig. 6. Calculated value of $e^{-C / T_{i}}\left(1743-T_{i}\right)$ vs. temperature for $\mathrm{Na}_{2} \mathrm{O}-\mathrm{SiO}_{2}$ specimens containing $40 \%$ liquid.

The relation developed is similar to that Preston used to describe crystal growth rates from viscous liquids.

\section{References}

${ }^{1}$ R. B. Sosman, Phases of Silica, pp. 75,121 . Rutgers University Press, New Brunswick, New Jersey, 1965.

${ }^{2}$ W. Hugill and W. J. Rees, "Influence of Iron Oxide on the Rate of Quartz Inversion in Lime and Lime-Clay Bonded Silica Bricks," Trans. Brit. Ceram. Soc., 30 [10] 321-29 (1931). 3 R. W. Grimshaw, J. Hargreaves, and A. L. Roberts," Kinetics of the Quartz Transformation," ibid., 55 [1] 36-56 (1956).

"W. L. De Keyser and R. Cypres, "Formation of Tridymite: Combined Action of Lime and Alkali Oxides," Silicates Ind., 25 [3] 109-37 (1960).

"Abd-El-Moneim Abou-El-Azm and H. Moore, "Study of the Reaction Rates Between Silica and Other Oxides at Various Temperatures: I," J. Soc. Glass Technol., 37 [176] 129-54T (1953); "II," pp 155-67T; “III," [177] 168-81T; "IV," pp. 182-89T; "V," pp. 190-212T.

S S. B. Holmquist, T. F. Berry, and L. Zwell, "Quantitative X-Ray Analysis of Silica Minerals," Am. Ceram. Soc. Bull., 37 [7] $317-21(1958)$

${ }^{7}$ H. P. Klug and L. E. Alexander, X-Ray Diffraction Procedures. John Wiley \& Sons, Inc., New York, 1954.

${ }^{8}$ H. R. Swift, "Effect of Magnesia and Alumina on Rate of Crystal Growth in Some Soda-Lime-Silica Glasses," J. Am. Ceram. Soc., 30 [6] 170-74 (1947).

- W. D. Kingery, Introduction to Ceramics. John Wiley \& Sons, Inc., New York, 1960.

10 L. H. Van Vlack; pp. 1-14 in Microstructure of Ceramic Materials. Natl. Bur. Std. (U. S.) Misc. Publ., No. 257, 106 pp., 1964 .

11 Eric Preston, "Crystallization in Silicate Slags and Glasses," Trans. Faraday Soc., 37 [4] 209-20 (1941). 